\title{
Comparison of three airborne laser bathymetry data sets for monitoring the German Baltic Sea Coast
}

\author{
Yujin Song*a , Joachim Niemeyer ${ }^{\mathrm{a}}$, Wilfried Ellmer ${ }^{\mathrm{b}}$, Uwe Soergel ${ }^{\mathrm{c}}$, Christian Heipke ${ }^{\mathrm{a}}$ \\ ${ }^{a}$ Institute of Photogrammetry and GeoInformation, Leibniz Universität Hannover, Nienburger Str.1, \\ 30167 Hannover, Germany; \\ ${ }^{\mathrm{b}}$ Federal Maritime and Hydrographic Agency, Neptunallee 5, 18057 Rostock, Germany; \\ ${ }^{\mathrm{c}}$ Institute of Geodesy, Technische Universität Darmstadt, Franziska-Braun-Str.7, 64287 Darmstadt, \\ Germany
}

\begin{abstract}
Airborne laser bathymetry (ALB) can be used for hydrographic surveying with relative high resolution in shallow water. In this paper, we examine the applicability of this technique based on three flight campaigns. These were conducted between 2012 and 2014 close to the island of Poel in the German Baltic Sea. The first data set was acquired by a Riegl VQ-820-G sensor in November 2012. The second and third data sets were acquired by a Chiroptera sensor of Airborne Hydrography AB in September 2013 and May 2014, respectively. We examine the 3D points classified as seabed under different conditions during data acquisition, e.g. the turbidity level of the water and the flight altitude. The analysis comprises the point distribution, point density, and the area coverage in several depth levels. In addition, we determine the vertical accuracy of the 3D seabed points by computing differences to echo sounding data. Finally, the results of the three flight campaigns are compared to each other and analyzed with respect to the different conditions during data acquisition. For each campaign only small differences in elevation between the laser and the echo sounding data set are observed. The ALB results satisfy the requirements of IHO Standards for Hydrographic Surveys (S-44) Order 1b for several depth intervals.
\end{abstract}

Keywords: Airborne laser bathymetry (ALB), 3D point cloud, Secchi depth, coastal, accuracy

\section{INTRODUCTION}

An accurate description of the seabed is essential for enabling a precise and safe navigation of ships as well as a reliable coastal monitoring and management. To measure the water depth and shape of the seabed various ship-based remote sensing techniques such as single-beam echo sounder, multi-beam echo sounder and side-scan sonar have been developed. However, data acquisition using these traditional methods for surveying the seabed topography is both costly and time consuming. Furthermore, it is difficult to obtain such information in shallow water zones because these areas are often not accessible for vessels. A solution to cope with these issues is to use airborne laser bathymetry (ALB). This measurement technique is particularly suitable for data acquisition in shallow water zones, and it is able to provide continuously topographic data of both, land surface and shallow water zones. ALB is well suited for nearshore mapping because it provides 3D point data needed for a variety of purposes, e.g. navigation, nautical charting, shore protection, coastal structure evaluation, and emergency response $[1,2]$.

In this paper, we report on practical experience gained in the project 'Investigation in the use of airborne laser bathymetry in hydrographic surveying', in which the applicability of ALB for monitoring the German Baltic Sea Coast is analyzed in cooperation with the German Federal Maritime and Hydrographic Agency. Between 2012 and 2014, three flight campaigns were performed close to the island of Poel. We evaluate the 3D points classified as seabed in order to investigate the accuracy of the different sensors and the impact of environmental parameters.

\section{AIRBORNE LASER BATHYMETRY}

Airborne laser bathymetry (ALB) sensors usually emit green laser pulses (e.g. wavelength $\lambda=532 \mathrm{~nm}$ ) for the bathymetric measurement. This wavelength is able to penetrate the water column and is reflected from the seabed. Additionally, most sensors use a second wavelength in the infrared part of the spectrum $($ e.g. $\lambda=1064 \mathrm{~nm})$ for the topographic and water surface measurements. The infrared laser pulse is reflected from the water surface. As a result the

Remote Sensing of the Ocean, Sea Ice, Coastal Waters, and Large Water Regions 2015, edited by

Charles R. Bostater, Stelios P. Mertikas, Xavier Neyt, Proc. of SPIE Vol. 9638, $96380 Z$

(C) 2015 SPIE $\cdot$ CCC code: $0277-786 X / 15 / \$ 18 \cdot$ doi: $10.1117 / 12.2194960$

Proc. of SPIE Vol. 9638 96380Z-1 
water depth can be computed as the difference of the water surface peak and the seabed peak. The maximum depth which can be reached in this way is limited by the water turbidity, and is measured in terms of the so called Secchi depth. This indicator is defined as the maximum depth at which the human eye is able to detect a specific circular disk with a diameter of $30 \mathrm{~cm}$ in the water.

ALB was developed in the 1960s with the primary goal of finding submarines. Hickman and Hogg [3] proposed to use ALB for bathymetric survey. In the 1970s some ALB prototypes were successfully developed and tested [4]. In recent years this technique has become increasingly important due to improved hardware and better processing software. This development has also made possible the recording of the waveform of the backscattered signal [5]. In [6], a seabed map of sand and seagrass was produced using both the corrected waveform and underwater video data recorded during the flight campaign. Moreover, the classification of the ALB data was studied using inherent characteristics of the recorded waveforms [7, 8]. Pe'eri et al. [9] investigated ALB-based land-water interface algorithms with green-, red-, and infrared channel waveforms to detect the shoreline of rocks, vegetation and man-made features. As a further application ALB was applied to map submerged archaeological structures over large areas in high detail. The results showed that the technique is mature enough to be utilized for underwater heritage management [10]. In combination with side-scan sonar, shipwrecks were indentified and their dimensions could be measured [11]. Recently, full-waveform processing algorithms for single-wavelength ALB were investigated for a better extraction of seabed points $[12,13]$.

\section{DATA ACQUISITION}

\subsection{Study area}

To investigate the applicability of ALB monitoring for the German Baltic Sea Coast, three flight campaigns were performed close to the island of Poel in the German Baltic Sea. The test areas were of varying size with slightly different locations. In order to carry out a comparison under equal conditions, we focus only on the overlapping area of the three flight campaigns, which is $95.8 \mathrm{~km}^{2}$ in size. The location of the study area is shown in Figure 1. Most parts are covered by water, but the area also comprises some small shore regions. Concerning the water depth a variation can be observed from $0 \mathrm{~m}$ to the maximum depth of $23.2 \mathrm{~m}$. This value is deeper than the expected depth which is currently reached by ALB sensors under the available turbidity level; in fact it was chosen to determine the limitation of the penetration depth.

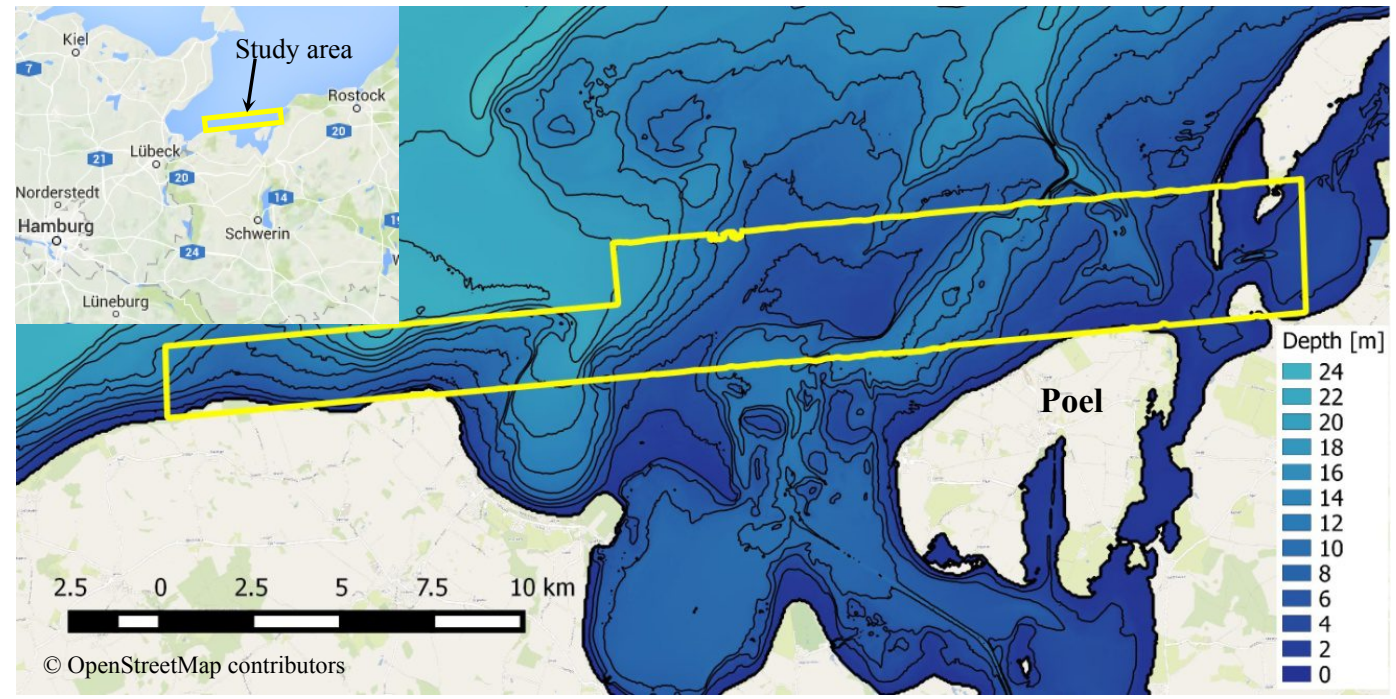

Figure 1. Overview of the study area, which is highlighted by the yellow boundary.

\subsection{Flight campaigns}

The first data set was acquired by Milan Geoservice GmbH, Germany, with a Riegl VQ-820-G Sensor in the beginning of November 2012. This sensor works with a green laser $(\lambda=532 \mathrm{~nm})$ solely. In the investigated overlapping area, 25 strips with an overlap of $70 \%$ were acquired. For this survey the pulse repetition rate was set to $149 \mathrm{kHz}$. The flying height was $500 \mathrm{~m}$ above ground level. A first quantitative analysis of the ALB data near the island of Poel was reported in $[14,15]$. The second data set was collected by TopScan GmbH, Germany, in the end of September 2013 with 
Chiroptera and HawkEye II sensors of Airborne Hydrography AB. The HawkEye II sensor can emit more powerful pulses with the drawback of a relatively low pulse rate of $4 \mathrm{kHz}$ compared to the Chiroptera sensor. Also, data from the HawkEye sensor were only available for areas which are too deep for obtaining measurements with the Chiroptera sensor. To enable a fair comparison between all sensors we therefore excluded the HawkEye data from our study. The third data set was gathered by Aerodata Surveys, the Netherlands, in mid-May 2014 with the Chiroptera sensor. For both Chiroptera flights the height was $400 \mathrm{~m}$ above ground. 23 strips with an overlap $30 \%$ and three cross-strips in the second campaign as well as 20 strips, again with an overlap 30\%, and one cross-strip in the third campaign were obtained. Using these two flight campaigns a comparison with respect to water turbidity was possible. The Chiroptera sensor is composed of two lasers, an infrared laser ( $\lambda=1064 \mathrm{~nm}, 200 \mathrm{kHz}$ pulse rate) and a green laser ( $\lambda=532 \mathrm{~nm}, 35 \mathrm{kHz}$ pulse rate). The green laser of the Riegl VQ-820-G sensor and the Chiroptera sensor are claimed to penetrate water to one and 1.5 Secchi depths, respectively, under good conditions $[16,17]$. Secchi depths were measured at several locations by vessels simultaneously to the laser data acquisitions. Table 1 shows the parameters of the three flights and the mean Secchi depths which were observed during each campaign.

Table 1. Parameters of the three flight campaigns.

\begin{tabular}{|c|c|c|c|}
\hline & First Campaign & Second Campaign & Third Campaign \\
\hline Date & 31 Oct. - 14 Nov. 2012 & 28-29 Sept. 2013 & $5-12$ May 2014 \\
\hline Sensor & Riegl VQ-820-G & AHAB Chiroptera & AHAB Chiroptera \\
\hline Flight height & $500 \mathrm{~m}$ & $400 \mathrm{~m}$ & $400 \mathrm{~m}$ \\
\hline Measurement rate & $-(\lambda=1064 \mathrm{~nm})$ & $200 \mathrm{kHz}(\lambda=1064 \mathrm{~nm})$ & $200 \mathrm{kHz}(\lambda=1064 \mathrm{~nm})$ \\
& $149 \mathrm{kHz}(\lambda=532 \mathrm{~nm})$ & $35 \mathrm{kHz}(\lambda=532 \mathrm{~nm})$ & $35 \mathrm{kHz}(\lambda=532 \mathrm{~nm})$ \\
\hline Overlap $^{2}$ & $70 \%$ & $30 \%$ & $30 \%$ \\
\hline Reachable depth & $1 \times$ Secchi depth & $1.5 \times$ Secchi depth & $1.5 \times$ Secchi depth \\
\hline Mean Secchi depth & $6.8 \mathrm{~m}$ & $8.0 \mathrm{~m}$ & $5.8 \mathrm{~m}$ \\
\hline
\end{tabular}

The three data sets were delivered in LAS-format that included the 3D point coordinates along with an intensity value. In order to compensate for the different speed of light in water and air, and to take into account the change of direction of the light at the water surface, the coordinates of the seabed points were appropriately corrected by the data providers. They additionally classified the points into the six classes water surface, seabed, underwater vegetation, underwater object, onshore, and noise. Some statistics of the classified points for the three data sets are summarized in Table 2. The number of points classified as water surface in the first campaign is clearly smaller than in the other campaigns, in spite of the higher strip overlap. Only few pulses result in two or more echoes, thus mainly single echoes are observed. This effect is also described in [18] for a river site using the same sensor. In addition, due to the higher flight altitude the total amount of the points is smaller compared to the two flights with the Chiroptera sensor, which result in similar numbers of points per class. In general the amount of points classified as underwater object is negligible, although a few rocks are known to be located in this area. As one result of the project it can be stated that the detection of underwater objects solely in ALB data is still challenging in our test sites.

Table 2. Statistics of the classified points.

\begin{tabular}{|c|c|c|c|c|c|c|}
\hline & \multicolumn{2}{|c|}{ First Campaign } & \multicolumn{2}{|c|}{ Second Campaign } & \multicolumn{2}{|c|}{ Third Campaign } \\
\hline Class $\backslash$ Sensor & \multicolumn{2}{|c|}{ Riegl VQ-820-G } & \multicolumn{2}{|c|}{ AHAB Chiroptera } & \multicolumn{2}{|c|}{ AHAB Chiroptera } \\
\hline Water surface & $14,637,978$ & $(15.4 \%)$ & $118,412,469$ & $(42.0 \%)$ & $94,489,927$ & $(33.2 \%)$ \\
\hline Seabed & $57,807,774$ & $(60.9 \%)$ & $98,839,172$ & $(35.1 \%)$ & $91,636,326$ & $(32.2 \%)$ \\
\hline Underwater vegetation & 41,237 & $(0.00 \%)$ & $15,483,702$ & $(5.50 \%)$ & $14,377,054$ & $(5.05 \%)$ \\
\hline Underwater object & 0 & $(0.00 \%)$ & 180 & $(0.00 \%)$ & 0 & $(0.00 \%)$ \\
\hline Onshore & $22,138,957$ & $(23.3 \%)$ & $49,037,845$ & $(17.4 \%)$ & $84,271,762$ & $(29.6 \%)$ \\
\hline Sum & \multicolumn{2}{|c|}{$94,848,546$} & \multicolumn{2}{|c|}{$281,773,368$} & \multicolumn{2}{|c|}{$284,785,069$} \\
\hline
\end{tabular}

\footnotetext{
${ }^{1}$ as specified by the manufacturer
} 


\section{EVALUATION OF THE DATA SETS}

In this chapter we examine the 3D points classified as seabed at different depths. We also analyze the vertical accuracy of the 3D points with respect to the depth obtained by echo sounding in Section 4.4. In order to eliminate the effects of turbidity we give the result in terms of fractions of Secchi depth rather than in actual depth, by dividing the actual depth by the Secchi depth.

In order to characterize the seabed depth we use echo sounding data, which were measured by the Federal Maritime and Hydrographic Agency of Germany over the last 20 years. The horizontal distance between neighboring points of these measurements lies between approximately 5 and $50 \mathrm{~m}$. A number of recent ship-based measurements, carried out in a few small areas, verified that the morphology from echo sounding is in general still up-to-date. Thus, the older echo sounding data which cover the entire study area (except the very shallow water zones) can be considered as reference data for our analysis.

To evaluate ALB data sets according to Order 1a/1b of IHO Standards for Hydrographic Surveys (S-44) [19], a grid with a cell size of $5 \mathrm{~m}$ was generated from the data using a linear Delaunay interpolation method as implemented in Matlab [20]. The Secchi depth data were also interpolated, with a grid resolution of $10 \mathrm{~m}$. Dividing the depths of the interpolated echo sounding data by the corresponding interpolated Secchi values leads to a normalized seabed depth grid, in which the depths are represented in relation to Secchi depths. Since the very shallow water zones were not accessible for vessels, the normalized seabed depth between 0 and approximately 0.2-0.5 times the Secchi depth are incomplete.

\subsection{Point distribution}

The point distributions of the 3D points classified as seabed of each campaign are shown in Figure 2.

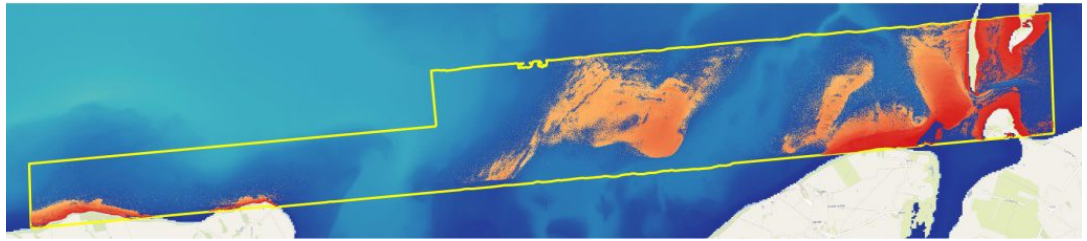

(1)

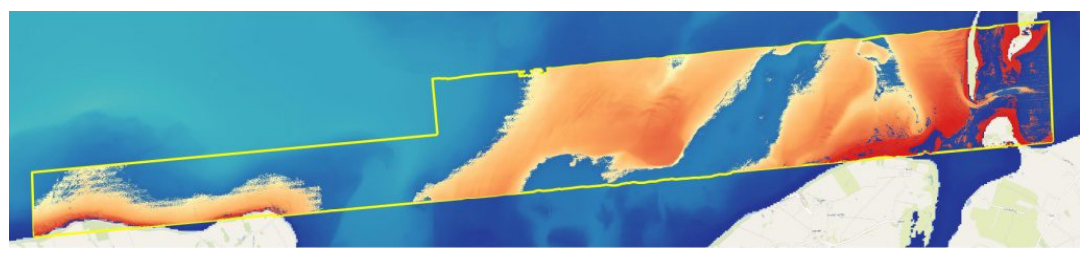

(2)

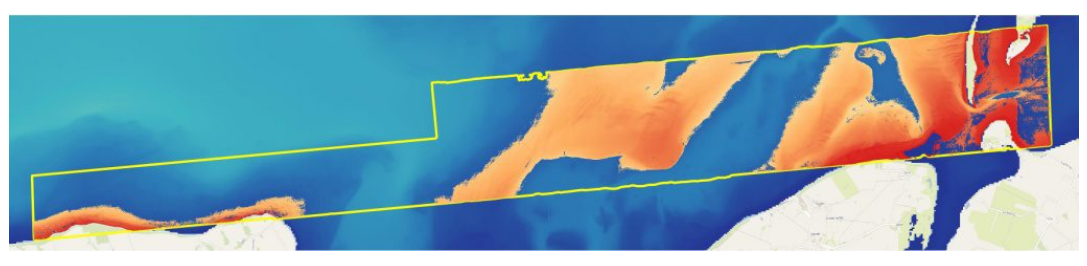

(3)

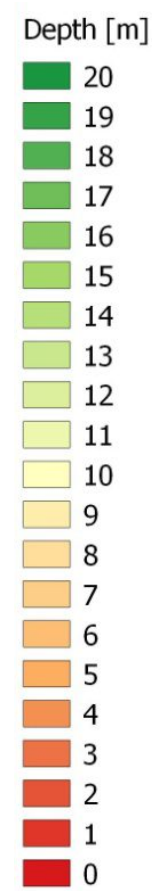

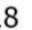

.6

\section{5} .

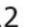
11 10

Figure 2. Distribution of the seabed points; (1) first campaign, (2) second campaign, (3) third campaign.

The seabed could be observed approximately up to $5 \mathrm{~m}$ water depth by the Riegl VQ-820-G sensor in the first campaign in November 2012. For the second and third campaign the same sensor Chiroptera with the same flight altitude was used. However, due to the different turbidity conditions during data acquisition the detected depths are different. In the second campaign in September 2013 the laser reached up to approximately $10 \mathrm{~m}$, but in the last campaign in May 2014 the penetration depth was about $7 \mathrm{~m}$ owing to the poorer average Secchi depth in comparison to the second campaign. 


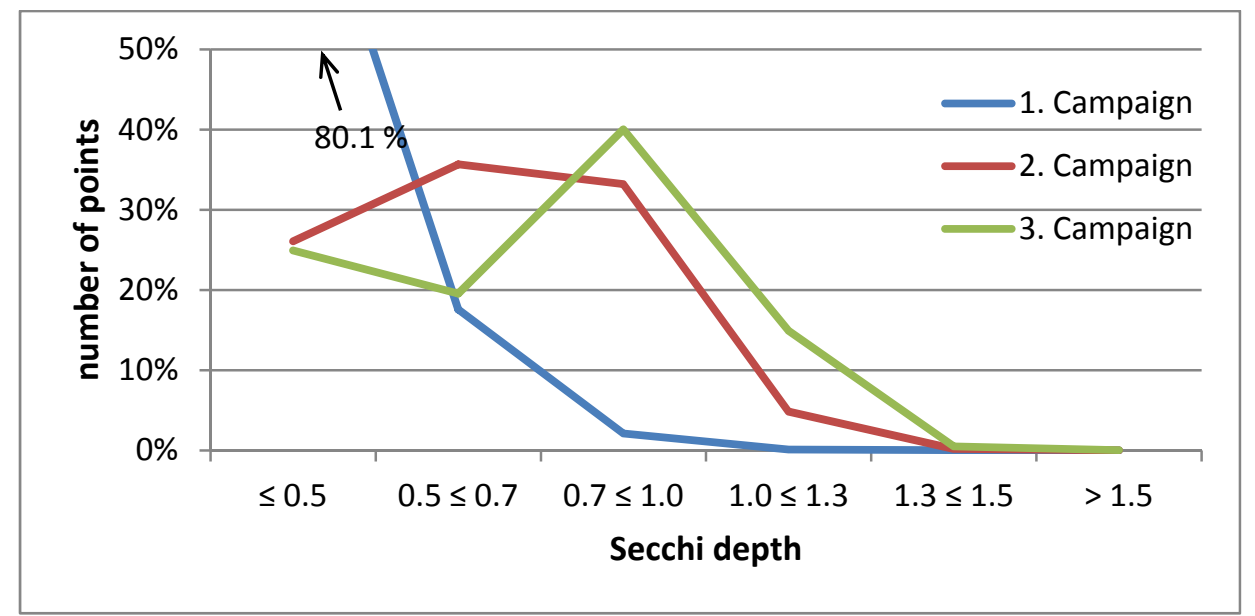

Figure 3. Number of seabed points in several normalized seabed depth intervals.

In addition to the quantitative analysis, we investigate the point distribution with respect to the normalized seabed depth. The result is presented in Figure 3, which shows the percentage of seabed points in several depth intervals. For the first campaign the observed seabed points mainly lie in the range of up to $0.7 \times$ Secchi depth, the curve then falls strictly monotonously. For the second and third campaign most of the points lie in the range of up to $1.3 \times$ Secchi depth. In contrast to the first campaign maximum values appear at $0.5-1.0 \times$ Secchi depth. Of course, it has to be kept in mind that the covered area per depth interval differs from campaign to campaign (see Figure 2, and also Section 4.3).

\subsection{Point density}

In this section we examine the density of the seabed points based on the normalized seabed depth. The results are given in Figure 4 presenting the number of seabed points per $\mathrm{m}^{2}$ at an interval of $0.1 \times$ Secchi depth. For the calculations the amount of points within one $5 \times 5 \mathrm{~m}^{2}$ grid cell is divided by 25 for normalization reasons. In contrast to Figure 3 the influence of the varying area size of a particular depth level is eliminated in this case. As mentioned above the shallow region between 0 and $0.2-0.5 \times$ Secchi depth is not complete. In the first campaign the point density decreases with increasing depth. Up to $0.5 \times$ Secchi depth the results of the first campaign provide a better point density than the other campaigns, probably due to the higher measurement rate. The shapes of the point density distribution curves for the other two campaigns are similar to each other. Their maxima are at approximately 2.4 points $/ \mathrm{m}^{2}$ and they decrease relatively slowly.

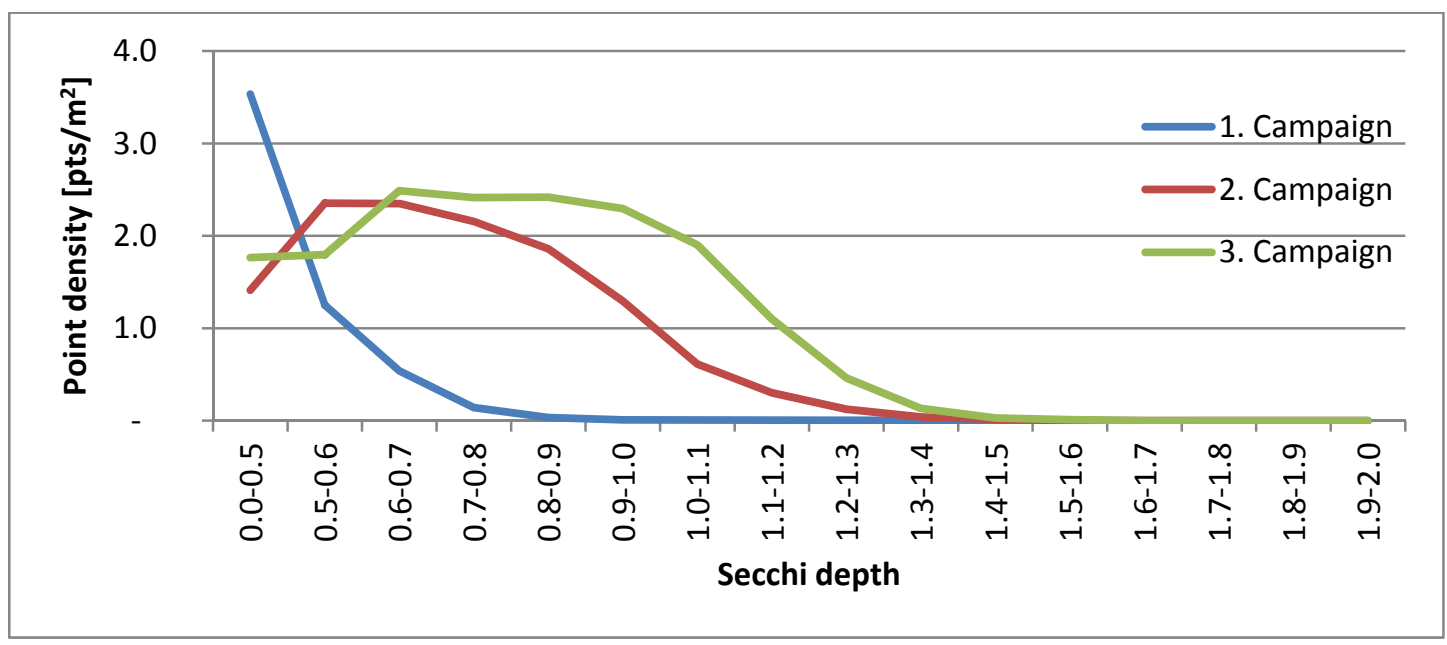

Figure 4. Point density of the seabed points with respect to the normalized seabed depth. 


\subsection{Area coverage}

In this section we analyze the percentage of seabed area which was actually covered by ALB points in several Secchi depth levels. The reference area is derived from the corresponding normalized seabed depth grid. Binary masks from the ALB points classified as seabed were generated for each campaign. At each grid cell $\left(5 \times 5 \mathrm{~m}^{2}\right)$ the mask was set to true if the cell contained at least one ALB seabed point, otherwise the grid cell was set to false. An approximation of the area covered by the ALB data was then determined by counting the grid cells corresponding to a particular depth level, that are set to true (see Figure 5).

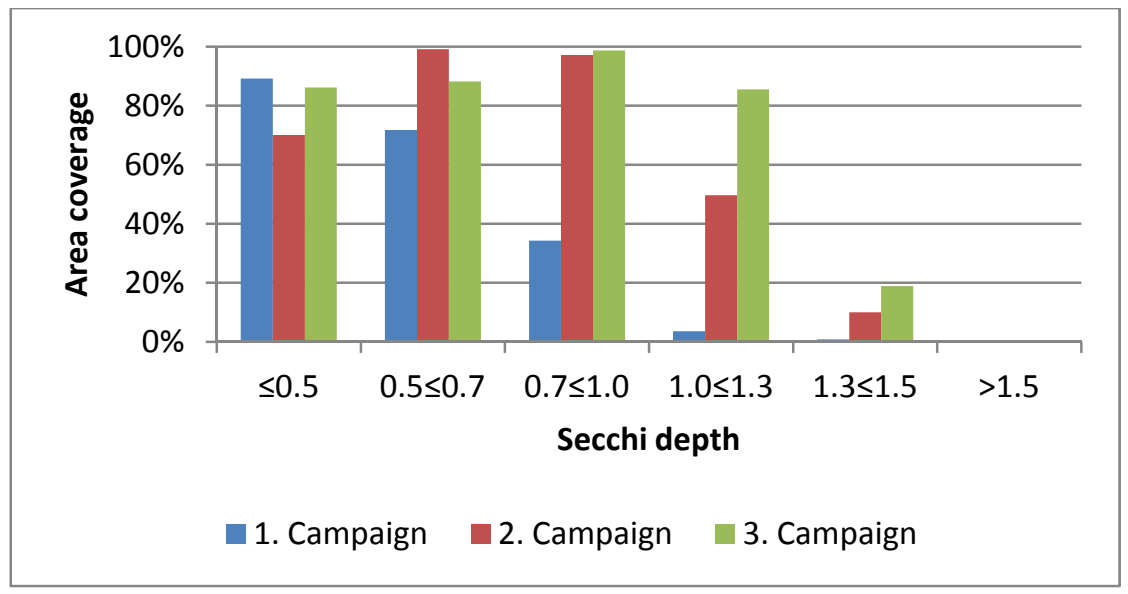

Figure 5. Coverage area by seabed points in comparison to the reference area.

For the first campaign the coverage of the laser points decreases steadily with increasing depth. By far most of the area was detected in the very shallow water. After $0.7 \times$ Secchi depth the number of points and, thus, also the covered area rapidly decreases. In contrast, over $70 \%$ of the seabed area is covered by laser points for the second and third campaign up to $1.0 \times$ Secchi depth. At a level of $1.0 \times$ to $1.3 \times$ Secchi depth the coverage decreases significantly, and regions deeper than $1.3 \times$ Secchi depth are only rarely observed.

\subsection{Vertical accuracy}

Of particular interest for the evaluation of the data is the vertical accuracy because it is relevant for many applications. We analyze the vertical accuracy of the 3D points classified as seabed by computing the difference in depth for each echo sounding point to the closest cell of an interpolated laser grid. Only points with a horizontal distance of less than $5 \mathrm{~m}$ to the grid cell are considered to cope with errors of wrong assignments. The differences between the laser grid and the echo sounding data are shown in Figure 6 and Table 3.

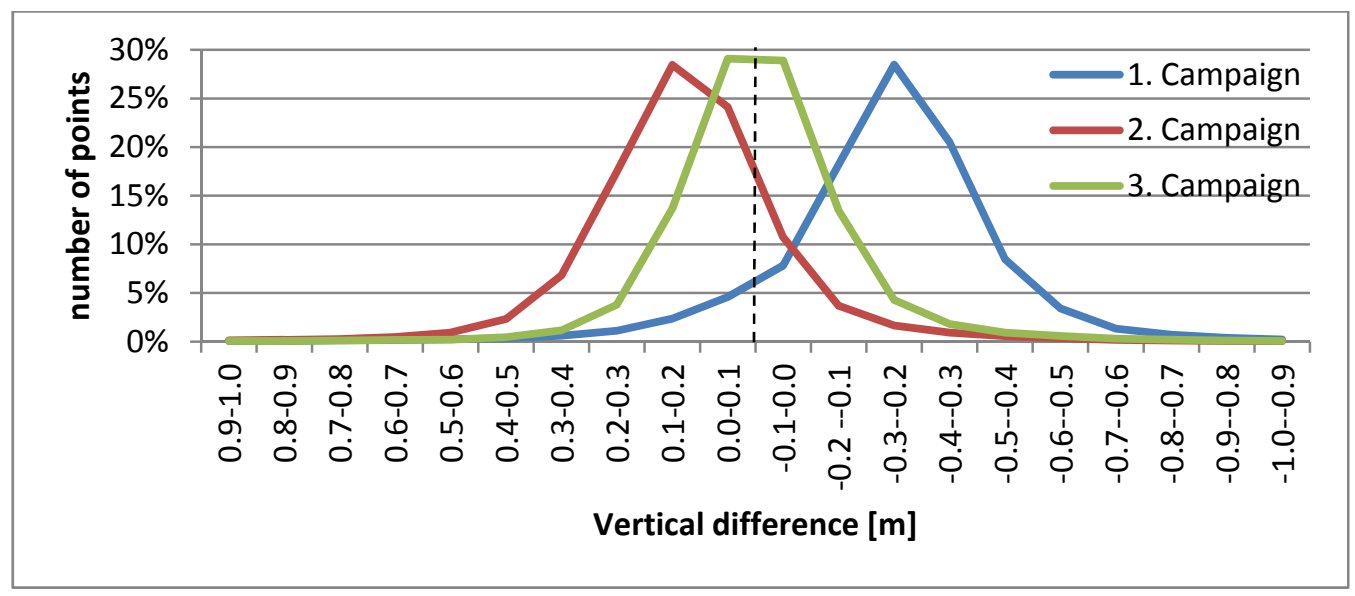

Figure 6. The differences between laser grid and echo sounding points for each campaign in $0.1 \mathrm{~m}$ intervals. 
Table 3. Distribution of the differences between a laser grid and echo sounding points in different intervals.

\begin{tabular}{|c|c|c|c|}
\hline Difference & First campaign & Second campaign & Third campaign \\
\hline $\mathbf{0 0 . 1} \mathbf{~ m}$ & $12.4 \%$ & $34.9 \%$ & $58.0 \%$ \\
\hline $\mathbf{0 . 3} \mathbf{~ m}$ & $62.6 \%$ & $86.1 \%$ & $93.2 \%$ \\
\hline $\mathbf{0 . 5} \mathbf{~ m}$ & $92.5 \%$ & $96.8 \%$ & $97.6 \%$ \\
\hline$\pm \mathbf{1 . 0} \mathbf{~ m}$ & $99.3 \%$ & $99.5 \%$ & $99.5 \%$ \\
\hline
\end{tabular}

A negative sign of vertical differences as for the first campaign in Figure 6 indicates that most parts of the laser grid lie under echo sounding points. On the other hand, a positive sign like the second campaign shows the laser grid lying above echo sounding points.

As depicted in Table 3, the seabed points of the third campaign are most similar to the echo sounding data. More than half of the differences are smaller than $\pm 0.1 \mathrm{~m}$. Additionally, the best results are also observed in the other three intervals. In contrast, the point cloud of the first campaign has the largest vertical deviation to the echo sounding data. Only $12.4 \%$ of the differences lie in the $\pm 0.1 \mathrm{~m}$ interval and $62.6 \%$ in the $\pm 0.3 \mathrm{~m}$ interval. However, most of the differences (over 92.5\%) of each campaign are smaller than $0.5 \mathrm{~m}$.

Concerning the quality of the data, laser bathymetry must at least meet the constraints of the IHO Standards for Hydrographic Surveys (S-44), Order 1b specifications to partly substitute ship-based bathymetry. These standards require one laser point every $5 \times 5 \mathrm{~m}^{2}$ (and even full sea floor coverage for Order 1a). The maximum allowable total horizontal uncertainty (THU) and total vertical uncertainty (TVU) at a 95\% confidence level are defined by

$$
\begin{gathered}
T H U_{\max }=5 m+5 \% \text { depth, } \\
T V U_{\max }= \pm \sqrt{(0.5 m)^{2}+(0.013 * \text { depth })^{2}} .
\end{gathered}
$$

The thresholds are the same for Orders $1 \mathrm{a}$ or $1 \mathrm{~b}$. In addition, to satisfy the requirements of Order 1a it must be possible to detect cubic obstacles of a size of larger than $2 \mathrm{~m}$ in depths up to $40 \mathrm{~m}$. In this study the focus is only on TVU because it is more critical for ship navigation, and the horizontal accuracy is difficult to compute from our data due to missing prominent objects under water. The vertical quality analysis based on Order $1 \mathrm{~b}$ of IHO (S-44) is listed in Table 4. The cells highlighted in yellow represent depths upon one times the Secchi depth, light orange cells indicate depths between $1 \times$ and $1.5 \times$ Secchi.

\begin{tabular}{|c|c|c|c|c|}
\hline \multirow{2}{*}{ Depth [m] } & \multirow{2}{*}{$\mathrm{TVU}_{\max }[\mathrm{m}]$} & \multicolumn{3}{|c|}{ Number of points within $\mathrm{TVU}_{\max }$} \\
\hline & & 1. Campaign & 2. Campaign & 3. Campaign \\
\hline $0-1$ & \pm 0.50 & $88.5 \%$ & $93.1 \%$ & $91.8 \%$ \\
\hline $1-2$ & \pm 0.50 & $92.2 \%$ & $92.7 \%$ & $94.6 \%$ \\
\hline $2-3$ & \pm 0.50 & $92.6 \%$ & $90.4 \%$ & $94.4 \%$ \\
\hline $3-4$ & \pm 0.50 & $93.8 \%$ & $92.9 \%$ & $97.1 \%$ \\
\hline $4-5$ & \pm 0.50 & $94.8 \%$ & $98.6 \%$ & $98.4 \%$ \\
\hline $5-6$ & \pm 0.51 & $94.2 \%$ & $99.2 \%$ & $99.2 \%$ \\
\hline $6-7$ & \pm 0.51 & $91.7 \%$ & $98.7 \%$ & $99.3 \%$ \\
\hline $7-8$ & \pm 0.51 & $87.6 \%$ & $97.7 \%$ & $98.1 \%$ \\
\hline $8-9$ & \pm 0.51 & $82.7 \%$ & $96.8 \%$ & $92.2 \%$ \\
\hline $9-10$ & \pm 0.52 & $70.9 \%$ & $97.4 \%$ & $50.5 \%$ \\
\hline $10-11$ & \pm 0.52 & $64.3 \%$ & $96.3 \%$ & $0.0 \%$ \\
\hline $11-12$ & \pm 0.52 & $0.0 \%$ & $83.9 \%$ & - \\
\hline
\end{tabular}

Table 4. Vertical quality analysis in $1 \mathrm{~m}$ depth intervals. $95 \%$ must be reached to fulfill IHO Order $1 \mathrm{a} / \mathrm{b}$ 
The vertical accuracy of all three data sets in the very shallow water zone shows a relatively small amount of small difference between the laser grid and echo sounding points, which may be due to the poor echo sounding data. The first campaign does not satisfy the confidence level of $\mathrm{TVU}_{\max }$, but the percentage of differences came close to $95 \%$ between 4-6 $\mathrm{m}$ depth. The second and third campaigns fulfill the requirement of TVU $\mathrm{Uax}_{\max }$ up to $11 \mathrm{~m}$ and $8 \mathrm{~m}$ depth, respectively.

\section{CONCLUSION}

In this paper, we present some results of the project 'Investigation on the use of airborne laser bathymetry in hydrographic surveying', in which the applicability of the ALB for monitoring the German Baltic Sea Coast is being analyzed in cooperation with the German Federal Maritime and Hydrographic Agency. The goal is to investigate the ALB technique and to determine areas for which ALB is potentially more economical than ship-based echo sounding. For the first campaign a Riegl VQ-820-G sensor was used, which is designed up to one Secchi depth under certain conditions, but in the tests about $97.7 \%$ of the observed points classified as seabed have a depth of less than $0.7 \times$ Secchi depth. High point densities are observed in very shallow water regions. For the second and third campaign a Chiroptera sensor with a nominal penetration depth of $1.5 \times$ Secchi depth was used. The pulses reached up to $1.3 \times$ Secchi depth. On the one hand, the maximum point density is lower than the results obtained by the Riegl sensor, probably due to the lower pulse rate and the smaller strip overlap. On the other hand, the point density of the Chiroptera sensor decreases only slowly with depth. We also show that the shallow areas are well covered up to $0.7 \times$ Secchi depth by a Riegl sensor and up to $1.0 \times$ Secchi depth by a Chiroptera sensor. The vertical accuracy of ALB was investigated in a comparison to echo sounding and was compared to the IHO Standards for Hydrographic Surveys (S-44). In order to fulfill the requirements, $95 \%$ of the differences must be less or equal $\pm 0.5 \mathrm{~m}$. The results of the first campaign do not meet the demanded vertical accuracy standards, but for approx. $94 \%$ of the seabed points of a depth of 3-6 $\mathrm{m}$ the differences were within $\pm \mathrm{TVU}_{\max }$. The second and third campaign satisfied the requirement in 4-11 and 3-8 $\mathrm{m}$ depth, respectively. Overall, over $92.5 \%$ of the seabed points of the three campaigns showed depth differences of less than $0.5 \mathrm{~m}$ compared to the echo sounding data.

In future work the full waveform information will be used for a classification of the points into several seabed substrates and underwater vegetation.

\section{REFERENCES}

[1] Irish, J. L. and Lillycrop, W. J., "Scanning laser mapping of the coastal zone: the SHOALS system," ISPRS Journal of Photogrammetry and Remote Sensing 54(2), 123-129 (1999).

[2] Irish, J. L., McClung, J. K. and Lillycrop, W. J., "Airborne Lidar Bathymetry-The Shoals System," Bulletin International Navigation Association, 45-54 (2000).

[3] Hickman, G. D. and Hogg, J. E., "Application of an airborne pulsed laser for near shore bathymetric measurements," Remote Sensing of Environment 1(1), 47-58 (1969).

[4] Guenther, G. C., Cunningham, A. G., LaRocque, P. E. and Reid, D. J., "Meeting the accuracy challenge in airborne lidar bathymetry," Proc. EARSeL-SIG-Workshop LIDAR, Dresden/FRG, 1-27 (2000).

[5] Mallet, C. and Bretar, F., "Full-waveform topographic lidar: State-of-the-art," ISPRS Journal of Photogrammetry and Remote Sensing 64(1), 1-16 (2009).

[6] Wang, C. and Philpot W. D., "Using airborne bathymetric lidar to detect bottom type variation in shallow waters," Remote Sensing of Environment 106(1), 123-135 (2007).

[7] Narayanan, R., Sohn, G., Kim, H. B., and Miller, J. R., "Soft classification of mixed seabed objects based on fuzzy clustering analysis using airborne LIDAR bathymetry data," Journal of Applied Remote Sensing 5(1), 053534053534-24 (2011).

[8] Tulldahl, H. M. and Wikström S. A., "Classification of aquatic macrovegetation and substrates with airborne lidar," Remote Sensing of Environment 121, 347-357 (2012).

[9] Pe'eri, S., Morgan, L. V., Philpot, W. D. and Armstrong A. A., "Land-Water Interface Resolved from Airborne LIDAR Bathymetry (ALB) Waveforms," Journal of Coastal Reasearch 62, 75-85 (2011).

[10] Doneus, M., Doneus, N., Briese, C., Pregesbauer, M., Mandlburger, G. and Verhoeven, G., "Airborne laser bathymetry - detecting and recording submerged archaeological sites from the air," Journal of Archaeological Science 40(4), 2136-2151 (2013). 
[11] Shih, P. T., Chen, Y. and Chen, J., "Historic Shipwreck Study in Dongsha Atoll with Bathymetric LiDAR," Archaeological Prospection 21(2), 139-146 (2014).

[12] Wang, C., Li, Q., Liu, Y., Wu, G., Liu, P. and Ding, X., "A comparison of waveform processing algorithms for single-wavelength LiDAR bathymetry," ISPRS Journal of Photogrammetry and Remote Sensing 101, 22-35 (2015).

[13] Pan, Z., Glennie, C., Hartzell, P., Fernandez-Diaz, J. C., Legleiter, C. and Overstreet, B., "Performance Assessment of High Resolution Airborne Full Waveform LiDAR for Shallow River Bathymetry," Remote Sensing 7(5), 51335159 (2015).

[14] Niemeyer, J. and Soergel, U., "Opportunities of Airborne Laser Bathymetry for the Monitoring of the Sea Bed on the Baltic Sea Coast," ISPRS-International Archives of the Photogrammetry, Remote Sensing and Spatial Information Sciences 1(2), 179-184 (2013).

[15] Niemeyer, J., Kogut T., and Heipke, C., "Airborne Laser Bathymetry for Monitoring the German Baltic Sea Coast," DGPF Tagung, (2014).

[16]Riegl laser measurement systems, "Riegl VQ-820-G Datasheet," Riegl, 24 March 2015, http://www.riegl.com/uploads/tx_pxpriegldownloads/DataSheet_VQ-820-G_2015-03-24.pdf.

[17] AHAB Chiroptera, "Brochure AHAB Chiroptera," October 2012, Airborne Hydrography AB, http://www.airbornehydro.com.

[18] Mandlburger, G., Pfennigbauer, M., and Pfeifer, N., "Analyzing Near Water Surface Penetration in Laser Bathymetry - a Case Study at the River Pielach," ISPRS Annals of the Photogrammetry, Remote Sensing and Spatial Information Sciences 1(2), 175-180 (2013).

[19] International Hydrographic Organization, "IHO Standards for Hydrographic Surveys Special Publication No. 44," 5th Edition, International Hydrographic Bureau, Monaco, 1-28 (2008).

[20] Mathworks, "Matlab $2015 \quad$ Documentation,

http://de.mathworks.com/help/matlab/ref/griddata.html (4 August 2015). 